\title{
Influence of Carbon Nanosheets on the Behavior of 1,2-Dipalmitoyl-sn-glycerol-3-phosphocholine Langmuir Monolayers
}

\author{
Ruth Muñoz-López ${ }^{1}$, Eduardo Guzmán ${ }^{1,2, * \mathbb{C}}$, Maria Mercedes Velázquez ${ }^{3} \mathbb{1}$, \\ Laura Fernández-Peña ${ }^{1}$, María Dolores Merchán ${ }^{3}\left(\mathbb{D}\right.$, Armando Maestro ${ }^{4}$, Francisco Ortega ${ }^{1,2}$ (D) \\ and Ramón G. Rubio ${ }^{1,2}$ \\ 1 Departamento de Química Física, Facultad de Ciencias Químicas, Universidad Complutense de Madrid. \\ Ciudad Universitaria s/n, 28040 Madrid, Spain; ruthmuno@ucm.es (R.M.-L.); \\ laura.fernandez.pena@ucm.es (L.F.-P.); fortega@quim.ucm.es (F.O.); rgrubio@quim.ucm.es (R.G.R.) \\ Instituto Pluridisciplinar, Universidad Complutense de Madrid. Paseo Juan XXIII, 1, 28040 Madrid, Spain \\ 3 Departamento de Química Física, Facultad de Ciencias Químicas, Universidad de Salamanca. Plaza Caídos \\ s/n, 37008 Salamanca, Spain; mvsal@usal.es (M.M.V.); mdm@usal.es (M.D.M.) \\ 4 Institut Laue-Langevin. 71 Avenue des Martyrs, CS 20156, 38042 Grenoble, France; maestro@ill.fr \\ * Correspondence: eduardogs@quim.ucm.es; Tel.: +34-91-394-4107
}

Received: 23 December 2019; Accepted: 8 January 2020; Published: 10 January 2020

\begin{abstract}
Carbon nanomaterials are widespread in the atmospheric aerosol as a result of the combustion processes and their extensive industrial use. This has raised many question about the potential toxicity associated with the inhalation of such nanoparticles, and its incorporation into the lung surfactant layer. In order to shed light on the main physical bases underlying the incorporation of carbon nanomaterials into lung surfactant layers, this work has studied the interaction at the water/vapor interface of carbon nanosheets $(\mathrm{CN})$ with Langmuir monolayers of 1,2-Dipalmitoyl-sn-glycerol-3-phosphocholine (DPPC), with this lipid being the main component of lung surfactant layers and responsible of some of the most relevant features of such film. The incorporation of CN into DPPC Langmuir monolayers modifies the lateral organization of the DPPC at the interface, which is explained on the basis of two different effects: (i) particles occupy part of the interfacial area, and (ii) impoverishment of the lipid composition of the interface due to lipid adsorption onto the $\mathrm{CN}$ surface. This results in a worsening of the mechanical performance of the monolayers which may present a negative impact in the physiological performance of lung surfactant. It would be expected that the results obtained here can be useful as a step toward the understanding of the most fundamental physico-chemical bases associated with the effect of inhaled particles in the respiratory cycle.
\end{abstract}

Keywords: particles; lipids; Langmuir monolayer; lung surfactant; pollution; dilational rheology; toxicity; carbon nanosheets

\section{Introduction}

Particulate materials are widespread in modern society, presenting interest in different scientific and industrial fields. On one side, particles are common in different technological fields, ranging from the fabrication of drug delivery platforms and biosensors in medicine to the stabilization of foams and emulsions with interest in cosmetics or food science, and from surface-enhanced Raman spectroscopy (SERS) to tertiary oil recovery [1]. On the other side, human activity is associated with a continuous injection of particles to the atmosphere mainly due to the combustion process of fossil fuels in powder plants, vehicles, or other combustion engines. These carbonaceous particles combined with other 
pollutants are part of the atmospheric aerosols, having an extraordinary impact on environmental and human health $[2,3]$.

Among the nanomaterials from carbonaceous sources, carbon nanotubes and graphene nanosheets are probably accounted as two of the most extended technological nanomaterials due to their special physico-chemical properties [4-6]. The wide spread of the above-mentioned particles has recently raised many questions about the potential risks associated with their inhalation, which presents a special importance because particles' inhalation has been frequently associated with the emergence of respiratory and cardiac diseases $[7,8]$. Several studies have related the initial steps of the diseases to the penetration and transport of the inhaled particles, mainly those with the smallest sizes (hydrodynamic diameter below $1 \mu \mathrm{m}$ ), through the respiratory tract to the alveolar cavities where they are deposited and interact with the lung surfactant layer [9-12].

Lung surfactant is a complex fluid, formed mainly by lipids and proteins, which overlays the inner wall of the alveoli, presenting a main role for mammals' survival because it enables reducing the work required for breathing, i.e., reduces the surface tension at the alveolar air/liquid interface, stabilizing lungs during the compression/expansion cycles of breathing and avoiding alveolar collapse [13]. Furthermore, lung surfactant is the first protection barrier against inhaled pathogens and aerosols. Therefore, any dysfunction in the normal performance or composition of the lung surfactant layer can affect the normal respiratory process, and simultaneously facilitate the penetration of pathogens' agents to other tissues [14]. This is particularly important because several studies have shown that particles can interact with fluid layers, altering their composition, lateral organization, and physico-chemical properties, especially the rheological one [15-19]. Therefore, the understanding of the interaction of particles with lung surfactant models is particularly important because it can help to deepen the potential impact of inhaled particles on the properties of this system, which may be useful as a preliminary tool for the evaluation of the potential toxicity of inhaled particles [20-23].

The complexity of the lung surfactant system makes it difficult to study the particles' impact in their performance using in vivo assays, which imposes the use of simple physico-chemical models for helping in the understanding of the potential toxicity of inhaled particles [20,24]. Thus, considering that the performance of lung surfactant is associated with their adsorption as a thin film at the interfacial region existing between the alveolar fluid overlaying the alveolar inner wall and the air contained in alveoli, the Langmuir monolayer at water/vapor interfaces may be considered as a useful tool for deepening the physico-chemical bases underlying the mechanical function of the lung surfactant layer, and the impact of the incorporation of nanoparticles on its performance $[20,21,24]$. Furthermore, the chemical complexity of lung surfactant makes it necessary to reduce the number of chemical species included in the used model to deepen the role of each single component in the interfacial properties of the lung surfactant layer and to understand how nanoparticles modify its performance. The most extended model used in studies related to the interaction of lung surfactant layers with nanoparticles is the 1,2-Dipalmitoyl-sn-glycerol-3-phosphocholine (DPPC) [10,25-38]. This lipid is the main component of the lung surfactant (about $40 \mathrm{wt} \%$ of the total weight), playing a key role in the ability of lung surfactant to decrease the surface tension until quasi-null values and in the formation of ordered monolayers with a high lateral cohesion. It is worth mentioning that the Langmuir monolayer of such lipid does not allow accounting for the re-spreading processes, occurring during expiration, of the material squeezed out from the interface during inspiration, which requires considering the role of two of the surface active proteins of the lung surfactant (mainly the surface proteins B, SP-B, and C, SP-C) [13,39-42]. However, DPPC Langmuir monolayers can be considered as a good tool for a preliminary evaluation of the worsening of the physico-chemical properties of lung surfactant layers as a result of the incorporation of solid particles, even though the biophysical relevance of these studies may be rather limited $[23,43]$.

This study tries to help in the understanding of the impact of carbonaceous nanomaterials on the physico-chemical properties of lung surfactant models. For this purpose, the interaction of carbon nanosheets $(\mathrm{CN})$, as an example of graphene-like material, with DPPC Langmuir monolayers, has been 
studied on the basis of the modification of the two-dimensional (2D) phase diagram due to the incorporation of the $\mathrm{CN}$ and their impact in the rheological performance of DPPC layers. We have followed a procedure adapted from that previously discussed by Guzmán et al. [44]. Although the effect of different carbonaceous nanomaterials such as carbon nanotubes, carbon black, and fullerenes on the interfacial properties of lung surfactant has been previously described [35,38,43-48], there is a poor knowledge on the effect of graphene and its derivatives in such properties [49]. For this reason, in this work, a graphene-like material is used as a model of carbonaceous material. The wide spread of graphene makes it necessary to obtain a preliminary evaluation of its potential impact in the properties of lung surfactant layers. It is expected that the results contained herein may contribute to the understanding of the most fundamental physico-chemical bases that govern the impact of carbonaceous nanomaterials on the performance of lung surfactant layers.

\section{Materials and Methods}

\subsection{Materials}

1,2-Dipalmitoyl-sn-glycerol-3-phosphocholine (DPPC) was purchased from de Avanti Polar Lipids, Inc. (Alabaster, AL, USA) at $99.9 \%$ purity and used without further purification. The molecular weight of this lipid is $734.1 \mathrm{~g} / \mathrm{mol}$. Carbon nanosheets AVAN-graphene ${ }^{\circledR}(\mathrm{CN})$ were supplied by Avanzare Innovación Tecnológica S.L. (La Rioja, Spain). For the spreading of both DPPC and CN, solutions in chloroform (CHROMASOLVTM, for High Performance Liquid Chromatography, stabilized with ethanol) purchased from Fisher Scientific (Hampton, NY, USA) was used.

Ultrapure deionized water used for cleaning and experiments was obtained by a multi-cartridge purification system AquaMAX ${ }^{\mathrm{TM}}$-Ultra 370 Series (Young Lin Instrument Co., Ltd., Gyeonggi-do, Korea), presenting a resistivity higher than $18 \mathrm{M} \Omega \cdot \mathrm{cm}$, and a total organic content lower than $6 \mathrm{ppm}$. This water has a surface tension of $72.5 \mathrm{mN} / \mathrm{m}$ without any appreciable kinetics over several hours.

\subsection{Characterization of Carbon Nanosheets (CN)}

Powder X-Ray diffraction (XRD) patterns were used for characterizing the microstructure of $\mathrm{CN}$. $X$-ray diffraction patterns were obtained in the $10-40^{\circ}$ range $\left(0.05^{\circ}\right.$ step size, $2.6 \mathrm{~s}$ step time) using a Bruker D8 Advance powder diffractometer (Bruker Corp., Billerica, MA, USA) fitter with a $\mathrm{Cu}$ $\mathrm{K} \alpha 1,2$ radiation source $(\lambda=1.54050 \AA)$. The operating tube voltage and current were fixed in $40 \mathrm{kV}$ and $30 \mathrm{~mA}$, respectively. Interlayer spacing, $d_{002}$, values were obtained using Bragg's law for (002) reflection. The grain size, $C$, can be calculated, obtained from the (100) reflection, using Scherrer's equation [50]: $C=0.9 \lambda /(\beta \cos \theta)$, where $\beta$ represents the line width at half height in radians and $\theta$ the diffraction angle.

X-ray photoelectron spectra (XPS) of powder samples were measured in a VG Escalab 200R spectrometer (Fisons Instruments, Glasgow, UK). The instrument uses an excitation source of $\mathrm{Mg}$ $\mathrm{K} \alpha(\mathrm{h} v=1253.6 \mathrm{eV})$ radiation and a hemispherical electron analyzer. High-resolution spectra were recorded at $20 \mathrm{eV}$ analyzer pass energy. The residual pressure in the analysis chamber was kept under $4 \times 10^{-7}$ Pa during data acquisition.

\subsection{Study of Monolayers at the Water/Vapor Interface}

The study of the behavior of Langmuir monolayers was performed using a Langmuir trough Nima model 702 (Nima Technologies, Coventry, UK), equipped with two Delrin barriers allowing for symmetric compression/expansion of the free liquid surface. The total surface area of the Teflon trough is $700 \mathrm{~cm}^{2}$. The surface tension, $\gamma$, was measured using a force balance fitted with a paper Wilhelmy plate (Whatman CHR1 chromatography paper, effective perimeter $20.6 \mathrm{~mm}$, supplied by Sigma Aldrich, St. Louis, MO, USA), ensuring a zero-angle contact angle. Surface pressure, $\Pi$, may be obtained as the difference between the surface pressure of the pure water/vapor interface $\gamma_{w}$ and $\gamma$, i.e., $\Pi=\gamma_{w}-\gamma$. 
The lipid monolayers were spread at the water/vapor interface by dropping controlled volumes of DPPC from its solution in chloroform (concentration about $1 \mathrm{mg} / \mathrm{mL}$ or $1.36 \mathrm{mM}$ ) using a high-precision Hamilton syringe (Hamilton Company, Reno, NV, USA). This allows for controlling the surface concentration of DPPC, $\Gamma$, after the evaporation of the solvent. For all the experiments performed here, an initial interfacial density of DPPC $\Gamma_{0}=1.4 \mu \mathrm{mol} / \mathrm{m}^{2}$, corresponding to an area per molecule of about $120 \AA^{2}$, was spread at the water/vapor interface. To prepare the mixed monolayers, given amounts of $\mathrm{CN}$ were spread onto the preformed DPPC monolayers, again using chloroform as the spreading solvent. This procedure allows for obtaining a monolayer with the desired DPPC:CB weight ratio at the interface. All the experiments were performed at $30^{\circ} \mathrm{C}$.

The quasi-equilibrium isotherms for the spread monolayers were obtained measuring the surface pressure during the reduction of the area available for the monolayer, $A$, at a fixed compression rate $\left(5 \mathrm{~cm}^{2} / \mathrm{min}\right.$ ). This compression rate was chosen to avoid undesired non-equilibrium effects during the determination of the isotherms [51]. Compression was started after $1 \mathrm{~h}$ from the solution/dispersion spreading at the water/vapor interface. This time was checked to be enough to ensure the complete evaporation of the solvent and, in the presence of $\mathrm{CN}$, the achievement of the equilibrium state for the composite layer [44].

The Langmuir trough also enables for the evaluation of the dilational viscoelasticity of Langmuir monolayers of the pure lipid and after the incorporation of different amounts of $\mathrm{CN}$ using the oscillatory barrier method in a range of frequencies from $5 \mathrm{mHz}$ to $0.15 \mathrm{~Hz}$. A detailed description of this method is given elsewhere [16,52]. This method involves the application of a harmonic change of the interfacial area at a controlled frequency $v$ :

$$
A(t)=A^{0}+\Delta A \sin (2 \pi v t)
$$

where $A^{0}$ and $\triangle A$ are the reference interfacial area and the amplitude of the deformation, respectively. The harmonic change of the interfacial area leads to a stress response, $\Delta \Pi=\Pi^{0}-\Pi(t)$, which is related to the difference between the surface pressure of the reference state, $\Pi^{0}$, and the instantaneous value of the surface pressure, $\Pi(t)$. For those cases in which the amplitude of the deformation is small enough, i.e., deformations within the linear regime, it is possible to assume that the stress response also follows a sinusoidal profile with the same frequency as the deformation:

$$
\Pi(t)=\Delta \Pi \sin (2 \pi v t+\phi),
$$

where $\phi$ is the phase shift accounting for a possible delay of stress (surface pressure response) in relation to the strain (area deformation). Considering the above-mentioned linear response, the stress can be considered proportional to the deformation, $u(t)=\Delta A / A^{0}$ (elastic term), and to the rate of deformation, $\mathrm{d} u(t) / \mathrm{d} t$ (viscous term), which allows one to write the stress as:

$$
\Pi(t)=\varepsilon u(t)+\eta(\mathrm{d} u(t) / \mathrm{d} t)
$$

with $\varepsilon$ and $\eta$ being the dilational elasticity and viscosity, respectively. Considering the definition given by Equation (3) and assuming a generic harmonic perturbation, it is possible to obtain a definition for the complex dilational viscoelasticity:

$$
\varepsilon^{*}=\varepsilon+2 \pi v \eta \mathrm{i}
$$

where $\mathrm{i}=(-1)^{1 / 2}$. The analysis of the curves corresponding to the strain and stress in terms of Equations (1) and (2) give information about their amplitudes and the phase shift, enabling for the calculation of the dilational viscoelasticity. 


\section{Results and Discussion}

\subsection{CN Characterization}

We use X-ray diffraction (XRD) measurements to analyze the crystallinity of the material. The obtained diffractogram is shown in Figure 1. The two peaks observed correspond to the (002) and the (100) reflections [53]. The latter is associated with the basal distance appearing at $2 \theta \sim 43^{\circ}$, which results in a value of $0.21 \mathrm{~nm}$. These peaks have been previously observed in the XRD spectrum of graphene oxide synthesized from graphite [53] and might be due to O-groups attached to the basal plane or other kinds of defects [54,55]. It is worth noting the absence of the peak I, centered at $2 \theta \sim 10^{\circ}$ which is typical from graphene oxides. Previous works have shown that this peak disappears after thermal reduction of graphene oxide. Therefore, the absence of this peak in this material means that the oxidation degree in this sample is low and the chemical composition must be close to that of reduced graphene oxide.

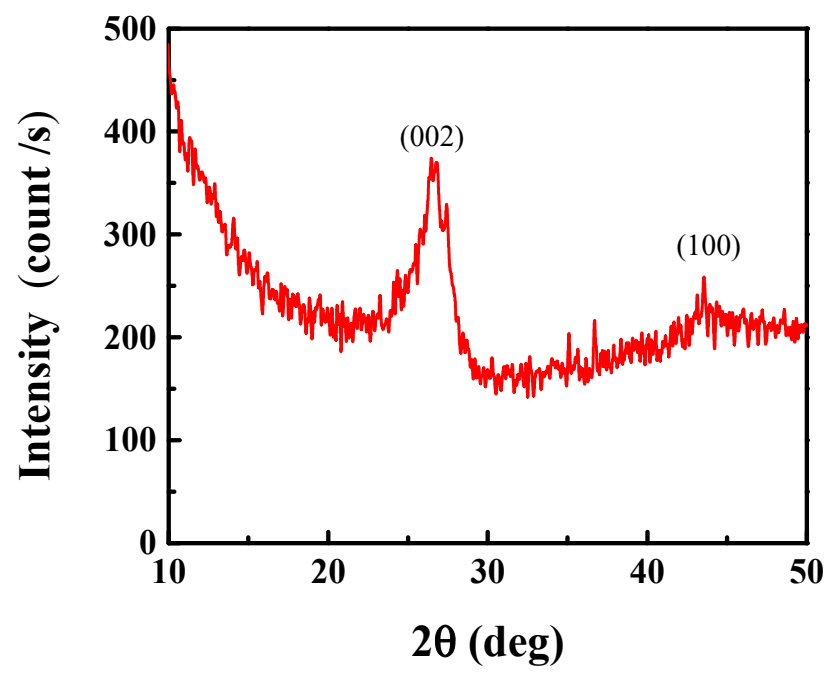

Figure 1. X-ray diffraction (XRD) diffractogram for carbon nanosheets $(\mathrm{CN})$. The reflections highlighted in the diffractogram allow for determining the interlayer distance (002 reflection) and the basal distance (100 reflection) of the $\mathrm{CN}$.

The interlayer distance between $\mathrm{sp}^{2}$ carbon layers may be related to the oxygen composition obtained by chemical analysis following the work by Claramunt et al. [55]. This interlayer distance is calculated using the Bragg's law on the 002 reflections, which can be considered the main feature of the diffractogram appearing at $2 \theta \sim 26.5^{\circ}$. The interlayer distance value between $\mathrm{sp}^{2}$ carbon layers calculated was $d_{002} \sim 0.33 \mathrm{~nm}$, which allows to estimate a percentage of oxygen of about $16 \%$. Besides, from the width at half height (2.046 radians) of this peak and the Scherrer's equation, the grain size, $C$, is calculated for this material, resulting in a value around $7 \mathrm{~nm}$, which agrees with values reported for reduced graphene oxides [50].

The chemical composition of the $\mathrm{CN}$ was analyzed using XPS. The obtained $\mathrm{C}_{1 \mathrm{~s}}$ and $\mathrm{O}_{1 \mathrm{~s}}$ core-level spectra are shown in Figure $2 a$ and Figure $2 b$, respectively. 

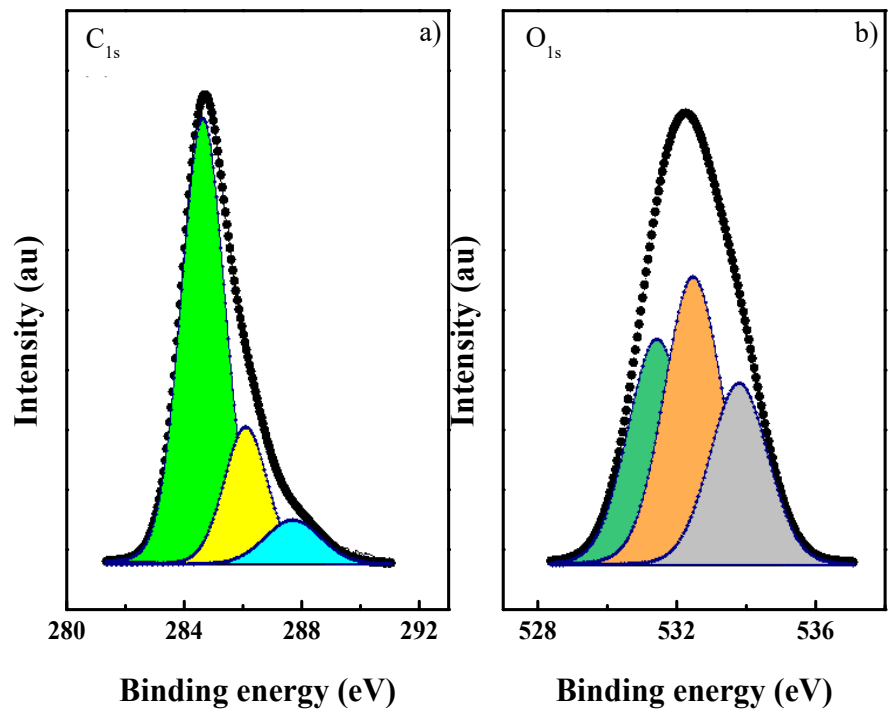

Figure 2. X-ray photoelectron spectra for $\mathrm{CN}$ : (a) $\mathrm{C}_{1 \mathrm{~s}}$ core level and (b) $\mathrm{O}_{1 \mathrm{~s}}$ core level. Circles are experimental data and solid lines are fits to the data. The functions in which the spectra are split are also shown as curved filled with different colours.

The results show that the $\mathrm{C}_{1 \mathrm{~s}}$ and $\mathrm{O}_{1 \mathrm{~s}}$ core-level spectra are asymmetric bands formed by three components. The $\mathrm{C}_{1 \mathrm{~s}}$ core-level spectrum presents the well-established components centered at 284.5, 286.2 , and 287.6, assigned to the aromatic carbon bonds ( $284.5 \mathrm{eV}), \mathrm{C}-\mathrm{O}$ bonds corresponding to alcohol or epoxy groups $(286.2 \mathrm{eV})$, and to $\mathrm{COO}^{-}$groups $(287.6 \mathrm{eV})$ [56]. The $\mathrm{O}_{1 \mathrm{~s}}$ core-level spectrum also present three components centered at 531.5, 532.6, and $533.8 \mathrm{eV}$, respectively. These components were reported for graphene oxides and assigned to $\mathrm{C}=\mathrm{O}, \mathrm{C}-\mathrm{O}$, and $\mathrm{O}-\mathrm{H}$ bonds [57]. Table 1 summarizes the band position and the fraction of different species.

Table 1. Binding energies and percentages of different groups obtained from X-ray photoelectron spectra (XPS).

\begin{tabular}{ccccc}
\hline $\begin{array}{c}\mathrm{C}_{1 \mathbf{s}} \\
\text { Emission }\end{array}$ & $\begin{array}{c}\text { Max. Binding Energy/eV } \\
\text { (Percentage) }\end{array}$ & $\begin{array}{c}\mathbf{O}_{1 \mathbf{s}} \\
\text { Emission }\end{array}$ & $\begin{array}{c}\text { Max. Binding Energy/eV } \\
\text { (Percentage) }\end{array}$ & O/C at \\
\hline $\mathrm{C}=\mathrm{C}$ & $284.8(71)$ & $\mathrm{C}=\mathrm{O}$ & $531.5(33)$ & \\
$\mathrm{C}-\mathrm{O}$ & $286.2(22)$ & $\mathrm{C}-\mathrm{O}$ & $532.6(41)$ & 0.154 \\
$\mathrm{C}=\mathrm{O}$ & $287.6(7)$ & $\mathrm{O}-\mathrm{H}$ & $533.8(26)$ & \\
\hline
\end{tabular}

It is worth mentioning that the O/C obtained from XPS in atomic units is $15.4 \%$. This value is in excellent agreement with the value estimated from the XRD diffractogram. Therefore, in the following, it will assume that $C N$ present a low oxidation degree $(\mathrm{O} / \mathrm{C}=0.154)$. However, it contains several O-groups attached to the basal plane.

\subsection{CN Incorporation into 1,2-Dipalmitoyl-sn-glycerol-3-phosphocholine (DPPC) Langmuir Monolayers}

The study of the effect of $\mathrm{CN}$ incorporation on the interfacial properties of DPPC monolayers at the water/vapor interface was performed by adding different amounts of $\mathrm{CN}$ from its dispersion in chloroform onto preformed DPPC monolayers, i.e., once the DPPC is spread at the bare interface, the $\mathrm{CN}$ are added from the top to the DPPC monolayer. It is clear that the addition procedure for CN can affect the lateral organization of the DPPC molecules existing at the interface, and the interactions between DPPC and CN. Thus, the equilibrium properties of the mixed monolayer, achieved upon chloroform evaporation, will be characterized by the specific conditions in which the mixing of $\mathrm{CN}$ and DPPC has occurred. It is worth mentioning that even though the monolayers studied in this work 
cannot be considered as strictly mixed monolayers, because the spreading of DPPC and CN is not made simultaneously from a premixed dispersion (first, the DPPC is spread at the pure water/vapor interface, and then the addition of the $\mathrm{CN}$ is made onto the preformed DPPC monolayer), for the sake of simplicity, the term mixed monolayers will be used within the manuscript to define the monolayers containing both the lipid and the particles. It is worth mentioning that the methodology followed for the preparation of the mixed layers has been chosen to ensure that the interaction between particles and lipid molecules occurs only at the water/vapor interface, similarly to what happens during the deposition of inhaled nanoparticles in the lung surfactant layer. However, two main differences between the results obtained in this work and the naturally occurring interaction of inhaled particles and the lung surfactant layer should be considered: (i) the presence of chloroform during CN addition may affect both the lateral packing of the DPPC molecules and the DPPC-CN interaction, and (ii) during the process of deposition of inhaled nanoparticles, the interaction of particles and the lung surfactant layer may be affected for specific mass transport boundary conditions which cannot be included in studies based in Langmuir monolayers. These may modify the scenario occurring when in vivo conditions are considered in relation to that presented in the current study. Despite the lung surfactant being a complex mixture formed by several lipids and proteins, which undergoes periodic deformations of its surface area, a first step toward the understanding of the effect of particles in lung surfactant layers is to study the incorporation of particles into model monolayers.

On the basis of the nature of particles, it may be expected that the interaction between $\mathrm{CN}$ and DPPC at the interface can occur according to two types of mechanisms: (i) electrostatic interactions between the negatively charged carboxylic groups on the $\mathrm{CN}$ surface and the ammonium group at the terminal end of the polar head of the DPPC molecules, and (ii) hydrophobic interaction between nanosheets and the hydrophobic tails of the lipid molecules, whose importance increases with the packing of the monolayer.

Particles' incorporation into the lipid layer was evaluated from the modification of the DPPC surface pressure $(\Pi)$-area per molecule $(A)$ isotherm $(\Pi-A$ isotherm) after the addition of $C N$. Figure 3 shows the $\Pi-A / A_{0}$ isotherm for DPPC monolayers in the presence of different weight fractions of $\mathrm{CN}, x_{c}$ (note that the area axis is represented as the compression degree $A / A_{0}$, where $A$ and $A_{0}$ are the area corresponding to a single molecule of DPPC at the interface, considering a monolayer of the pure lipid, and the area occupied by a DPPC molecule before to start the compression, i.e., after the lipid spreading, respectively). The value of $A_{0}$, was fixed for all the experiments, assuming a value of $120 \AA^{2} /$ molecule, which is equivalent to a DPPC interfacial density $\Gamma_{0}=1 / A_{0}=1.4 \mu \mathrm{mol} / \mathrm{m}^{2}$.

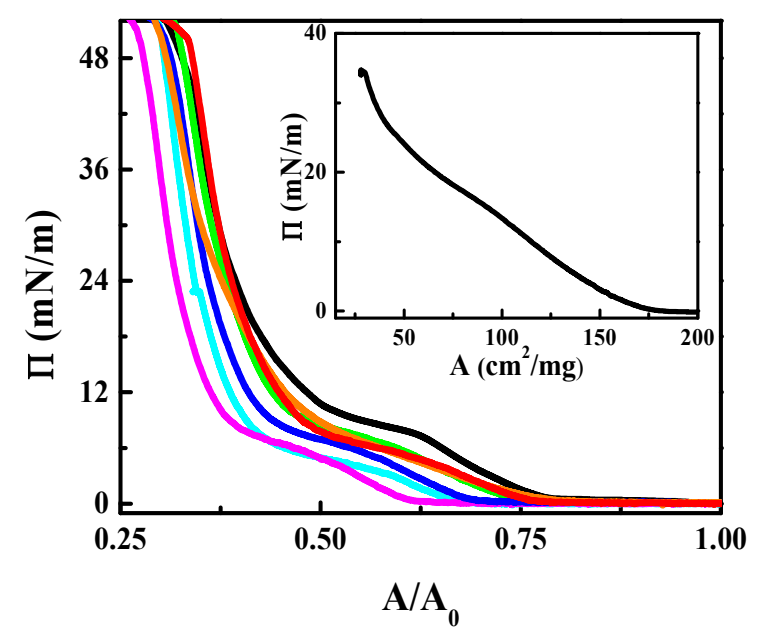

Figure 3. $\Pi-A / A_{0}$ isotherms for the Langmuir monolayer of 1,2-Dipalmitoyl-sn-glycerol-3-phosphocholine (DPPC) containing different amounts of CN. Each curve corresponds to DPPC monolayers with a different weight fraction of $\mathrm{CN}$ at the interface $\left(x_{c}\right)$ : (-) 0.00, (-) 0.12, (-) 0.26, (一) 0.30, (-) 0.33, (-) 0.42 and $(-)$ 0.50. The inset represents the isotherm obtained for the $\mathrm{CN}$ monolayer. 
The obtained DPPC isotherm is similar to those found in previous studies concerning this lipid [51,58-60], with the surface pressure increasing steeply as the interfacial density increases (i.e., as the $A / A_{0}$ ratio decreases), within the gas and liquid expanded (LE) phases, until reaching the region of coexistence between the LE and the liquid condensed (LC) phases (LE-LC coexistence). Along the LE-LC coexistence, a pseudo-plateau in the surface pressure was found, which is associated with the disappearance of the LE phase due to the re-orientation of the molecules to form a more ordered phase. Once the LE-LC coexistence is overcome $\left(A / A_{0} \sim 0.5\right)$, the surface pressure increases sharply with the packing density within the LE expanded phase and the solid one.

The inclusion of $\mathrm{CN}$ into the DPPC monolayer affects the isotherm of the pure lipids in two different ways: (i) alters the shape of the DPPC isotherm, and (ii) shifts the isotherm in relation to that corresponding to the pure DPPC. The former modification may be explained considering that particles' incorporation hinders the lateral packing of lipids at the interface, which is associated with the modification of the interactions occurring at the interface. Thus, the electrostatic interactions appearing between the carboxylic groups on $\mathrm{CN}$ and the polar head of the lipid affects the lateral packing of DPPC, as a result of the modification of the dipolar moment of the lipid at the interface [29,35]. The electrostatic interactions are also correlated to the shifting of the isotherm with the $\mathrm{CN}$ incorporation. The presence of $\mathrm{CN}$ shifts the isotherm to lower values of $A / A_{0}$, i.e., the presence of $\mathrm{CN}$ induces a behavior in DPPC monolayers similar to that expected considering a decrease of the effective surface concentration of DPPC at the interface, with this behavior presenting a strong dependence on the weight fraction of the particles. This is explained considering that in spite that particles remain trapped at the interface, taking out part of the area available for the reorganization of lipid molecules as was found for other hydrophobic particles [32,44], the electrostatic interaction between the carboxylic groups and the ammonium group of the DPPC polar head induces the adsorption of DPPC molecules onto the CN surface, decreasing the effective interfacial density of DPPC, and shifting, as a matter of fact, the isotherm to higher compression degrees. This behavior is just the opposite to that found when the interaction of carbon black with DPPC was considered [35,44], presenting a certain analogy with the behavior reported by Wang et al. [47,48], when the interaction of DPPC and different fullerenes was considered, and by Sheridan et al. [38] in their study of the interaction of commercial carbon particles and DPPC. It must be stressed that above a threshold value of $x_{c}$ (in the range $0.42-0.50$ ), the DPPC isotherm starts to shift to more expanded states (higher values of $A / A_{0}$ ) upon incorporation of $\mathrm{CN}$. This may be the result of a change in the orientation of $\mathrm{CN}$ at the interface, from a "face-in" orientation to an "edge-in" one, to minimize the electrostatic and steric repulsions between nanosheets. This change of the $\mathrm{CN}$ orientation at the interface may hinder the DPPC-CN interaction, with the reduction of the interfacial density of DPPC being less important, which supports the shifting of the isotherm to more expanded states. Figure 4 shows a cartoon of the different distribution of the lipids and the $\mathrm{CN}$ at the interface as a function of the $x_{c}$ value.

An alternative explanation for the changes on the isotherm as a result of the incorporation of nanoparticles is the possible stacking of $\mathrm{CN}$ as its interfacial density is increased. This was previously discussed by Wang et al. $[47,48]$ in their studies on the interaction of DPPC and different types of fullerenes. Thus, at the lowest values of $x_{c}$, it would be expected that individual CN may be incorporated at the interface removing DPPC molecules. This is compatible with the shifting of the isotherm to lower values of $A / A_{0}$ than those corresponding to pure DPPC monolayers. However, once a certain threshold value of $x_{c}$ is reached, the $\mathrm{CN}$ may start to stack, forming multilayers. This results in the decrease of the area accessible for the adsorption of DPPC molecules onto the CN surface, and, as a matter of fact, is less important than the DPPC removing from the interface, which means that the shift of the isotherm to higher values of $A / A_{0}$ may occur. It is worth noting that the above mechanisms lead to qualitatively similar results, with further studies being needed to discriminate the real origin of the isotherm shifts. 

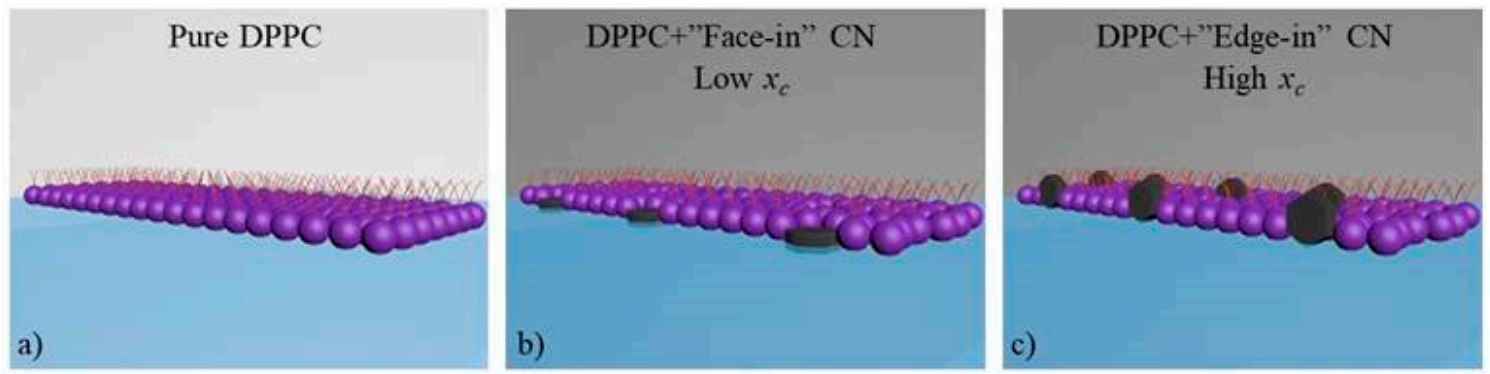

Figure 4. Scheme of the possible distribution of DPPC and $\mathrm{CN}$ at the water/vapor interface as $x_{c}$ increases: (a) Pure DPPC monolayer. (b) Monolayer of DPPC and CN in "face-in" orientation. (c) Monolayer of DPPC and CN in "edge-in" orientation. The different brightness of the upper region of panel $\mathrm{a}$ in relation to panels $\mathrm{b}$ and c pretends the existence of different environments (clean vs. polluted). Notice that the adsorption of DPPC molecules onto the CN surface is not shown explicitly in the scheme. It is expected that this adsorption can be more favored in the "face-in" (low values of $x_{c}$ ) orientation than in the "edge-in" (high values of $x_{c}$ ) one.

Additional insights on the effect of $\mathrm{CN}$ incorporation into the DPPC layers is provided from the quasi-static dilational elasticity obtained from the isotherm, as follows:

$$
\varepsilon_{0}=-A(\partial \Pi / \partial A)_{\mathrm{T}}
$$

Figure 5a shows the surface pressure dependences of the quasi-static dilational elasticity for DPPC monolayers including different weight fractions of $\mathrm{CN}$. The analysis of the dependences obtained for pure DPPC monolayers clearly shows three different features: (i) at the lowest surface pressures, the elasticity increases until a maximum related to the highly disordered LE phase in which a weak lateral packing between the molecules is expected, (ii) the elasticity drops with the increase of surface pressure down to reach a quasi-null value for the surface pressure corresponding to the LE-LC phase, and (iii) the elasticity increases within the LC phase up to its maximum value, which is related to an enhanced lateral packing, and then the elasticity drops as the monolayer approaches the collapse.
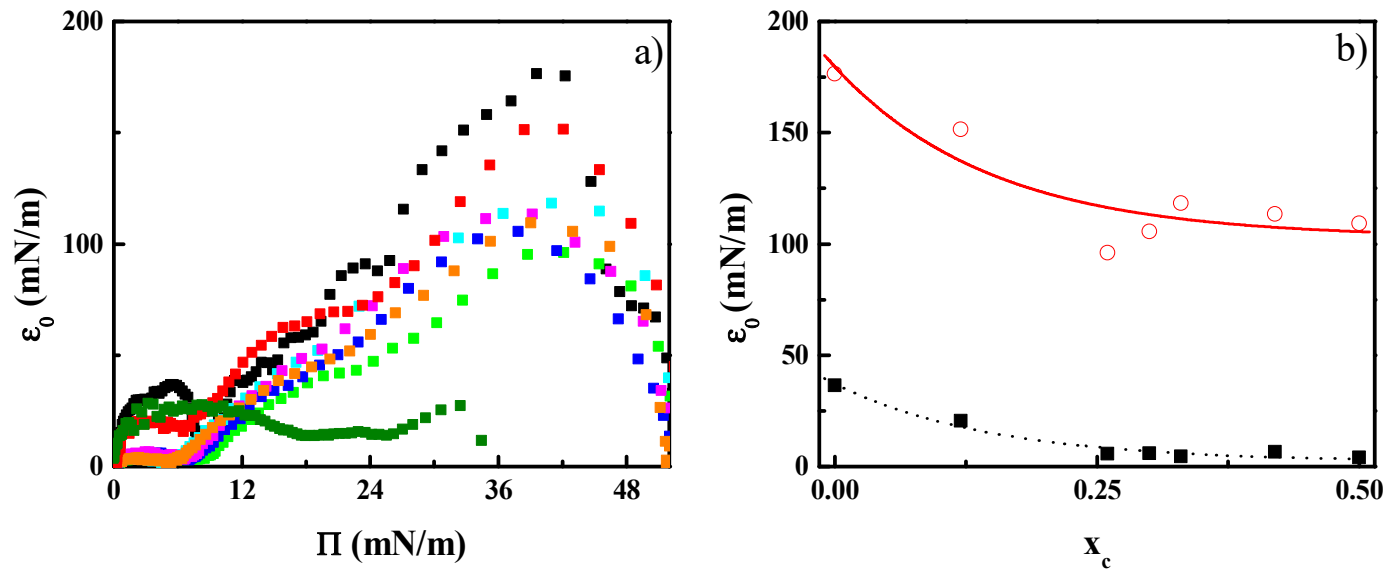

Figure 5. (a) Quasi-static dilational elasticity, $\varepsilon_{0}$, dependences on the surface pressure, $\Pi$, for the Langmuir monolayer of DPPC containing different amounts of CN. Each curve corresponds to DPPC

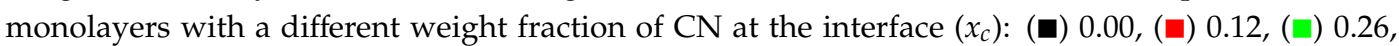
$(\square)$ 0.30, $(\square)$ 0.33, $(\square)$ 0.42, ( $\square$ ) 0.50 and $\square 1.00(\mathrm{CN})$. (b) Dependence of the limit values of the elasticity, $\varepsilon_{0}$, on the particle weight fraction, $x_{c}$, for the liquid expanded phase, LE $(\mathbf{\square}, \cdots . . . \cdot)$, and the liquid compressed phase, LC $(\mathrm{o},-)$. Notice that lines are guides for the eyes. 
The incorporation of $\mathrm{CN}$ dramatically affects the elasticity of the DPPC, decreasing the average elasticity within the entire phase diagram of the DPPC. This is explained considering the hindering of the lateral packing of the monolayer, which weakens the cohesive interactions. Furthermore, the increase of the $\mathrm{CN}$ amount leads to a behavior reminiscent to that appearing in monolayers of lipids with lacked lateral packing as those presenting a double bond in which a single liquid disordered phase appears in the isotherm [26]. The modification of the character of the monolayer is made clearer from the results in Figure 5b, where the maximum values of the elasticity for the LE and the LC are represented. The results clearly show that the elasticity of both phases is reduced with the value of $x_{C B}$, resulting from the hindrance to the DPPC reorientation due to the $\mathrm{CN}$ incorporation. Thus, the introduction of $\mathrm{CN}$ reduces the rigidity of the lipid monolayer, which can impact negatively on the mechanical performance of lung surfactant layers. This is because the rigidity of the lung surfactant film is essential for avoiding the alveolar collapse upon compression. Furthermore, the maximum packing for the monolayer can be found for lower values of surface pressure with the increase of the weight fraction of $\mathrm{CN}$. This could be rationalized considering that even though the lateral cohesion between the components existing in the monolayers is decreased, the interfacial density increases and consequently, the maximum packing of the monolayer occurs at lower values of the surface pressure.

Additional information about the effect of particles' incorporation in the interactions and the properties of DPPC monolayers may be obtained by applying the concepts of the thermodynamics of interfacial mixtures $[61,62]$. This provides an understanding about the contraction or expansion of the behavior of the monolayer for a fixed value of the surface pressure with respect to the conditions in which no interactions are involved, i.e., the ideal mixture. Ideal mixtures present an interfacial area which is defined as follows:

$$
A_{i d}=x_{D P P C} A_{D P P C}+x_{C} A_{C}
$$

where $A_{D P P C}$ and $A_{C N}$ correspond to the areas per a mass unit of DPPC and $\mathrm{CN}$ at the considered surface pressure for a monolayer of the pure components respectively, and $x_{D P P C}$ and $x_{C}$ refer to the weight fractions of DPPC and CN at the interface in the mixed monolayer. The differences associated with the mixing process at the fixed value of the surface pressure can be evaluated in terms of the excess area, $A^{E}$, defined as follows:

$$
A^{E}=A_{12}-A_{i d}
$$

where $A_{12}$ corresponds to the area per molecule corresponding to a fixed value of the surface pressure. Figure 6 shows the dependences of the $A^{E}$ on the weight fraction of $x_{C}$ at the interface for different values of the surface pressure.

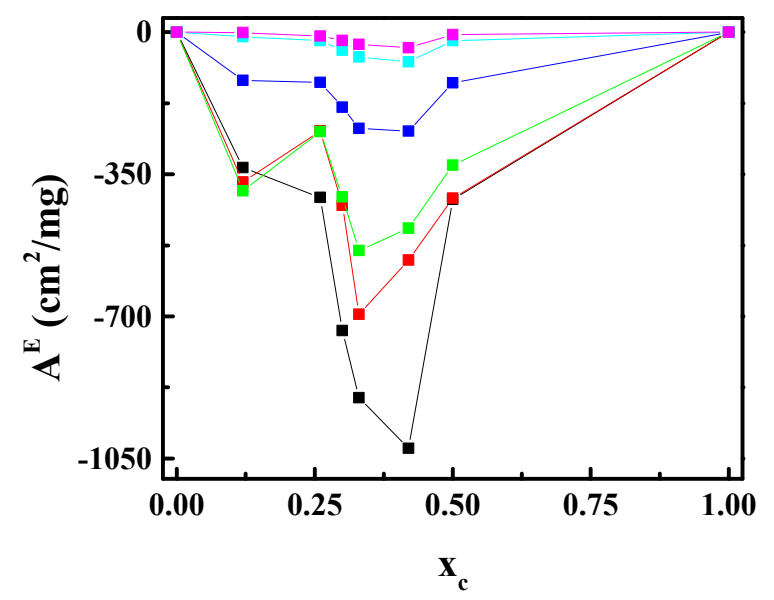

Figure 6. Dependences of the $A^{E}$ on the particle weight fraction, $x_{C}$, for different values of the surface

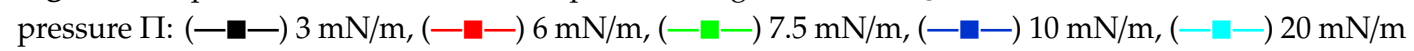
and (- - $30 \mathrm{mN} / \mathrm{m}$. Notice that lines are guides for the eyes. 
The results show that $A^{E}$ is negative values within the explored surface pressure range, independently of the weight fraction of the nanosheets. This is ascribed in most binary mixtures to a non-ideality on the mixing between the components at the interface, even though the cohesion interactions favor the miscibility [63]. Considering the particular characteristics of our mixed systems, the decrease of the area with respect to that expected for an ideal mixture, it can be explained considering the above discussed adsorption of the DPPC onto the surface of $\mathrm{CN}$ through the electrostatic interactions occurring between the ammonium groups of DPPC and the carboxylic groups on the CN surface.

Moreover, the analysis of the dependence of $A^{E}$ on the weight fraction for the different surface pressures, and the comparison of such dependences, help for deepening the interaction mechanism. Independently of the surface pressure considered, the excess area decreases with $x_{c}$, for the lowest values of $x_{c}$, and then it increases. This is explained considering the above commented change of the $\mathrm{CN}$ orientation at the interface which affects the interactions of the $\mathrm{CN}$ with the lipid molecules and between the different $\mathrm{CN}$. Therefore, the increase of $A^{E}$ with $x_{c}$ for the highest values of $x_{c}$ may be considered as a signature of the reduction of the DPPC $-\mathrm{CN}$ interactions. The analysis of the dependences of $A^{E}$ on the surface pressure evidences that increases of the packing diminishes the role of the interactions in the area reduction, probably as a result of the modification of the lateral packing as a result of the compression.

\subsection{Effect of CN Incorporation in the Dilational Response of DPPC Langmuir Monolayers}

The above discussion has focused so far on the effect of the $\mathrm{CN}$ on the equilibrium properties of DPPC monolayers. However, the behavior of most of the biologically relevant systems is closely related to their dynamics behavior. Therefore, the understanding of the effects of particles' incorporation into DPPC monolayers can be used as a preliminary test for evaluating the impact of particles in the functionality of lung surfactant layers, even though the conditions considered here are far from that corresponding to the typical respiratory cycle (higher frequencies and deformation amplitudes). However, the analysis of the dilational response provides information related to the effect of particles' incorporation in the relaxation mechanisms involved in the equilibration of the lipid layer $[27,28]$. This is possible from the analysis of the frequency dependences of the viscoelastic modulus (see Figure 7) obtained using the oscillatory barrier method at a fixed deformation amplitude within the linear response range ( $5 \%$ of the initial area). Note that the value of the viscoelastic modulus corresponding to the lowest frequency was considered to be the quasi-static dilational elasticity obtained from the isotherm, with the value of the frequency assigned to such value being obtained as the compression ratio, which for the experiments performed here assume a value of about $5 \cdot 10^{-4} \mathrm{~Hz}$.

The viscoelastic modulus-deformation frequency curves for DPPC monolayers show an inflexion point, with the exception of that obtained for the lowest value of the surface pressure. This inflexion point is associated with the characteristic frequency of the reorganization of the lipid molecules within the interface. The absence of such a relaxation process for the lowest surface pressure may be explained considering the low interfacial density, which allows a free reorganization of the molecules within the interface, which can involve time scales below (higher frequencies) those tested by oscillatory barrier experiments. The characteristic relaxation frequency can be obtained by fitting the experimental data to the following theoretical dependence according to the model proposed by Ravera et al. [64]:

$$
\left|\varepsilon^{*}\right|=\left[\left(E_{1}^{2}+\lambda^{2} E_{0}^{2}\right) /\left(1+\lambda^{2}\right)\right]^{1 / 2},
$$

where $\lambda=v_{R} / v$, with $v_{R}$ being the characteristic relaxation frequency, and $E_{0}$ and $E_{1}$ are the lower and upper limits of the elasticity within the considered frequency range. It is worth noting that for an insoluble monolayer as that studied here, the value of $E_{0}$ coincides with the quasi-static dilational elasticity obtained from the isotherm. 

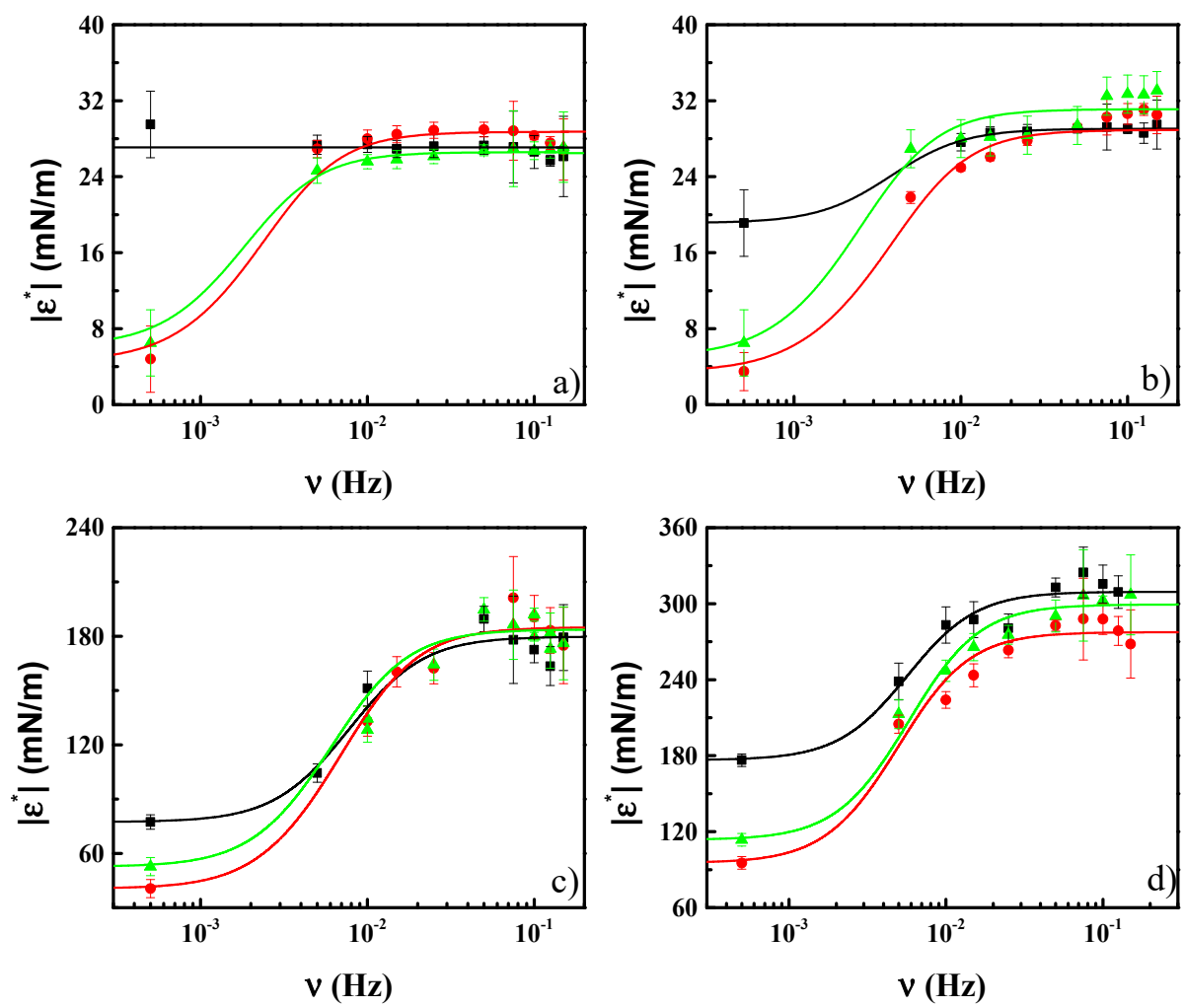

Figure 7. Experimental (symbols) and calculated, using Equation (7), (lines) dependences of the interfacial dilational viscoelasticity modulus on frequency at different values of the surface pressure $\Pi$ : (a) $3 \mathrm{mN} / \mathrm{m}$, (b) $7.5 \mathrm{mN} / \mathrm{m}$, (c) $20 \mathrm{mN} / \mathrm{m}$, and (d) $40 \mathrm{mN} / \mathrm{m}$. In the plots, each set of data corresponds to a different value of $x_{C N}:(\mathbf{\square},-) 0,(\mathbf{O},-) 0.26 \mathrm{mN} / \mathrm{m}$ and $(\Delta,-) 0.42$.

The analysis of the experimental curves for DPPC shows that the increase of the packing density, i.e., the increase of the surface pressure, leads to the increase of the value of the characteristic relaxation frequency (see Figure 8) up to the onset in the region in which molecules have high lateral packing (see values corresponding to $40 \mathrm{mN} / \mathrm{m}$ ). The initial increase may be explained by assuming that the lateral packing and ordering of the interfaces reduces the length-scale within which the relaxation occurs, and as a matter of fact, the relaxation becomes faster. Therefore, it is possible to assume that the lateral reorganization of the molecules is enhanced with the increase of the packing of the monolayer. For the highest packing density (high surface pressure), a slight decrease of the characteristic frequency was found, which may be associated with the loosening of the monolayer character of the DPPC film, involving more complex dynamics.
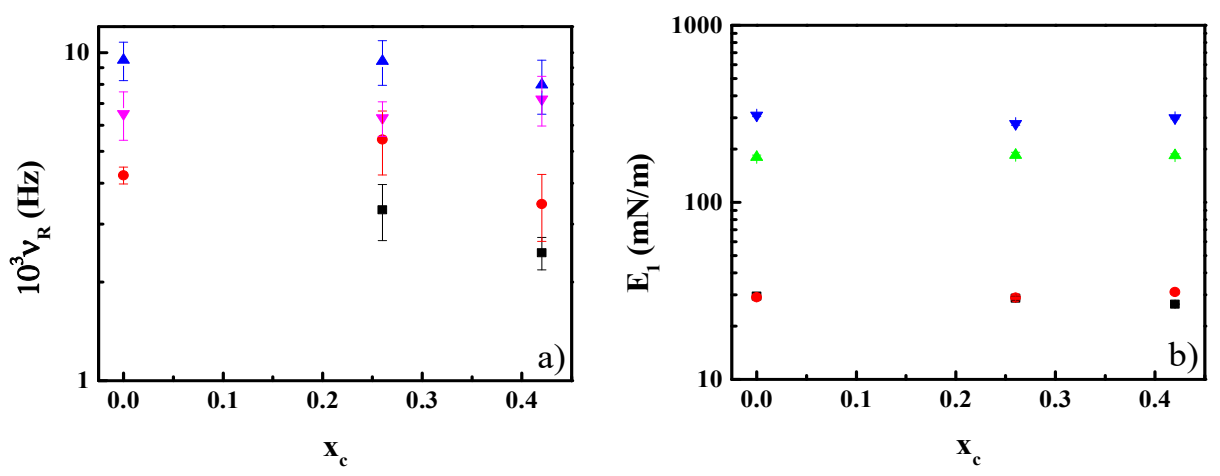

Figure 8. Dependences of (a) $v_{R}$ and (b) $E_{1}$ on the weight fraction of $x_{C N}$ for different values of the surface pressure $\Pi(\boldsymbol{\square}) 3 \mathrm{mN} / \mathrm{m},(\bullet) 7.5 \mathrm{mN} / \mathrm{m},(\boldsymbol{\Delta}) 20 \mathrm{mN} / \mathrm{m}$ and $(\boldsymbol{\nabla}) 40 \mathrm{mN} / \mathrm{m}$. 
The particles' incorporation does not significantly alter the scenario, and no additional relaxation processes appear due to the presence of particles. Furthermore, the characteristic frequency also increases with the interfacial packing (see Figure 8). The main differences upon particles' incorporation are associated with the emergence of a relaxation process for the lowest surface pressure. This may be the result of the excluded area effects which limits the length scale in which the reorganization of DPPC occurs, making this process accessible within the experimental window.

Figure 8 shows the dependences of $v_{R}$ and $E_{1}$ on the weight fraction of $\mathrm{CN}$ at the interface. The results corresponding to the dependences of $v_{R}$ (Figure 8a) show that in general, the relaxation processes are slightly slowed down (decrease of $v_{R}$ with the increase of $x_{c}$ ). This may rationalize considering the role of the molecules adsorbed onto the $\mathrm{CN}$ surface on the reorganization processes involving the equilibration of the interfacial layer [31].

The analysis of the dependences of $E_{1}$ (Figure $8 \mathrm{~b}$ ) evidences a slight decrease of the high-frequency limit of the elasticity with the increase of $x_{C N}$. This could also be ascribed to the worsening of the lateral cohesion of the DPPC layers as a result of the incorporation of the particles.

The results discussed here have shown that the incorporation of particles into lipid monolayers affect their equilibrium and dynamic properties. This is because particles distort the lateral organization of the lipid molecules, worsening, as a matter of fact, the cohesion of the monolayers, which can impact on a premature collapse when lung surfactant is concerned. Furthermore, particles modify the relaxation mechanism involved in the re-equilibration of the interfacial layers upon periodical compression-expansion deformation, which may influence the dynamics of re-entrance of material at the interface during the respiratory cycle, and consequently affect the normal physiological performance of lung surfactant layers.

\section{Conclusions}

The effect of the incorporation of CN into DPPC monolayers has been studied on the basis of the modification of the equilibrium isotherm and rheological properties of DPPC results. The analysis of the modification of the interfacial properties has been found to be dependent on the amount of particles, with particles affecting, in two different ways, the interfacial properties of lipid monolayers: (i) By decreasing the effective interfacial density of DPPC, and (ii) by reducing the area available for DPPC reorganization. The predominance of one such effect over the other is dependent on the interfacial density of particles, which modify the orientation of $\mathrm{CN}$ at the interface affecting the electrostatic interactions between the lipid and the particles. Furthermore, $\mathrm{CN}$ incorporation weakens the cohesion between lipid molecules, altering, as a matter of fact, the lateral packing of the molecules, which may affect the functionality of the interfacial layer. The results obtained here have evidenced that the analysis of the influence of particles' incorporation in both the equilibrium and rheological properties of DPPC layers can be used for the preliminary evaluation of the alterations induced by particles in biologically relevant systems, which presents special interest when particles' inhalation is concerned. However, it is worth noting that it is not possible to make a direct extrapolation of the results obtained using model Langmuir monolayers to the real situation occurring during inhalation. This is because in real systems, the mass transport during the deposition occurs under different mass boundary conditions to those considered here, which may affect the interactions between DPPC and $\mathrm{CN}$.

Author Contributions: Conceptualization, E.G.; Methodology, L.F.-P., E.G., and R.M.-L.; Software, E.G., and R.M.-L.; Validation, E.G., F.O., M.M.V., M.D.M., and R.G.R.; Formal Analysis, E.G., and R.M.-L.; Investigation, R.M.-L., E.G., L.F.-P., A.M., F.O., M.M.V., M.D.M., and R.G.R.; Resources, R.G.R., M.M.V., and F.O.; Data Curation, E.G.; Writing-Original Draft Preparation, E.G.; Writing—Review and Editing, E.G., A.M., F.O., M.M.V., M.D.M., and R.G.R.; Visualization, E.G.; Supervision, E.G., M.M.V., and R.G.R.; Project Administration, R.G.R.; Funding Acquisition, R.G.R., M.M.V., E.G. and F.O. All authors have contributed substantially to the work reported. All authors have read and agreed to the published version of the manuscript.

Funding: This work was funded by MINECO under grant CTQ2016-78895-R and by Banco Santander-Universidad Complutense, grant PR87/19-22513. 
Acknowledgments: The help of Patricia Guisado-Barrado in designing and preparing the artwork presented in Figure 3 is specially acknowledged. The C.A.I. of Espectroscopia y Correlación of the Universidad Complutense de Madrid is acknowledged for its availability in the use of its facilities. We also thank José L. García Fierro (Instituto de Catálisis y Petroleoquímica, CSIC, Madrid Spain) for XPS measurements and the X-Ray Diffraction service of the University of Salamanca for the XRD measurements.

Conflicts of Interest: The authors declare no conflict of interest. The funders had no role in the design of the study; in the collection, analyses, or interpretation of data; in the writing of the manuscript, or in the decision to publish the results.

\section{References}

1. Wu, C.-Y.; Ge, W. (Eds.) Particulate Materials: Synthesis, Characterisation, Processing and Modelling; Royal Society of Chemistry: Cambridge, UK, 2012.

2. Pavese, G.; Alados-Arboledas, L.; Cao, J.; Satheesh, S.K. Carbonaceous particles in the atmosphere: Experimental and modelling issues. Adv. Meteorol. 2014, 2014, 529850. [CrossRef]

3. Park, M.; Joo, H.S.; Lee, K.; Jang, M.; Kim, S.D.; Kim, I.; Borlaza, L.J.S.; Lim, H.; Shin, H.; Chung, K.H.; et al. Differential toxicities of fine particulate matters from various sources. Sci. Rep. 2018, 8, 17007. [CrossRef] [PubMed]

4. De Volder, M.F.; Tawfick, S.H.; Baughman, R.H.; Hart, A.J. Carbon Nanotubes: Present and Future Commercial Applications. Science 2013, 339, 535-539. [CrossRef]

5. Rauti, R.; Musto, M.; Bosi, S.; Prato, M.; Ballerini, L. Properties and behavior of carbon nanomaterials when interfacing neuronal cells: How far have we come? Carbon 2019, 143, 430-446. [CrossRef]

6. Zaytseva, O.; Neumann, G. Carbon nanomaterials: Production, impact on plant development, agricultural and environmental applications. Chem. Biol. Technol. Agric. 2016, 3, 17. [CrossRef]

7. Donaldson, K.; Seaton, A. A short history of the toxicology of inhaled particles. Part. Fibre Toxicol. $2012,9,13$. [CrossRef]

8. Beddoes, C.M.; Case, C.P.; Briscoe, W.H. Understanding Nanoparticle Cellular Entry: A Physicochemical Perspective. Adv. Colloid Interface Sci. 2015, 218, 48-68. [CrossRef]

9. Morawska, L.; Ayoko, G.A.; Bae, G.N.; Buonanno, G.; Chao, C.Y.H.; Clifford, S.; Fu, S.C.; Hänninen, O.; $\mathrm{He}, \mathrm{C}$; Isaxon, C.; et al. Airborne particles in indoor environment of homes, schools, offices and aged care facilities: The main routes of exposure. Environ. Int. 2017, 108, 75-83. [CrossRef]

10. Sosnowski, T.R. Particles on the lung surface-Physicochemical and hydrodynamic effects. Curr. Opin. Colloid Interface Sci. 2018, 36, 1-9. [CrossRef]

11. Rissler, J.; Gudmundsson, A.; Nicklasson, H.; Swietlicki, E.; Wollmer, P.; Löndahl, J. Deposition efficiency of inhaled particles (15-5000 nm) related to breathing pattern and lung function: An experimental study in healthy children and adults. Part. Fibre Toxicol. 2017, 14, 10. [CrossRef]

12. Dobrowolska, K.; Jablczynska, K.; Kondej, D.; Sosnowski, T.R. Interactions of insoluble micro- and nanoparticles with the air-liquid interface of the model pulmonary fluids. Physicochem. Probl. Miner. Process. 2018, 54, 151-162. [CrossRef]

13. Lopez-Rodriguez, E.; Pérez-Gil, J. Structure-function relationships in pulmonary surfactant membranes: From biophysics to therapy. Biochim. Biophys. Acta Biomembr. 2014, 1838, 1568-1585. [CrossRef] [PubMed]

14. Bernhard, W. Lung surfactant: Function and composition in the context of development and respiratory physiology. Ann. Anat. Anat. Anz. 2016, 208, 146-150. [CrossRef] [PubMed]

15. Maestro, A.; Guzman, E.; Ortega, F.; Rubio, R.G. Contact angle of micro- and nanoparticles at fluid interfaces. Curr. Opin. Colloid Interface Sci. 2014, 19, 355-367. [CrossRef]

16. Mendoza, A.J.; Guzman, E.; Martinez-Pedrero, F.; Ritacco, H.; Rubio, R.G.; Ortega, F.; Starov, V.M.; Miller, R. Particle laden fluid interfaces: Dynamics and interfacial rheology. Adv. Colloid Interface Sci. 2014, 206, 303-319. [CrossRef] [PubMed]

17. Maestro, A.; Santini, E.; Zabiegaj, D.; Llamas, S.; Ravera, F.; Liggieri, L.; Ortega, F.; Rubio, R.G.; Guzman, E. Particle and Particle-Surfactant Mixtures at Fluid Interfaces: Assembly, Morphology, and Rheological Description. Adv. Condens. Matter Phys. 2015, 2015, 917516. [CrossRef]

18. Maestro, A.; Santini, E.; Guzman, E. Physico-chemical foundations of particle-laden fluid interfaces. Eur. Phys. J. E 2018, 41, 97. [CrossRef]

19. Maestro, A.; Guzmán, E. Colloids at Fluid Interfaces. Processes 2019, 7, 942. [CrossRef] 
20. Guzmán, E.; Santini, E. Lung surfactant-particles at fluid interfaces for toxicity assessments. Curr. Opin. Colloid Interface Sci. 2019, 39, 24-39. [CrossRef]

21. Arick, D.Q.; Choi, Y.H.; Kim, H.C.; Won, Y.-Y. Effects of nanoparticles on the mechanical functioning of the lung. Adv. Colloid Interface Sci. 2015, 225, 218-228. [CrossRef]

22. Kondej, D.; Sosnowski, T.R. Alteration of biophysical activity of pulmonary surfactant by aluminosilicate nanoparticles. Inhal. Toxicol. 2013, 25, 77-83. [CrossRef] [PubMed]

23. Yang, Y.; Wu, Y.K.; Ren, Q.Z.; Zhang, L.G.; Liu, S.J.; Zuo, Y.Y. Biophysical Assessment of Pulmonary Surfactant Predicts the Lung Toxicity of Nanomaterials. Small Methods 2018, 2, 8. [CrossRef]

24. Sosnowski, T.R.; Kubski, P.; Wojciechowski, K. New experimental model of pulmonary surfactant for biophysical studies. Colloid Surf. A 2017, 519, 27-33. [CrossRef]

25. Guzman, E.; Liggieri, L.; Santini, E.; Ferrari, M.; Ravera, F. Influence of silica nanoparticles on phase behavior and structural properties of DPPC-Palmitic acid Langmuir monolayers. Colloids Surf. A 2012, 413, 280-287. [CrossRef]

26. Guzman, E.; Liggieri, L.; Santini, E.; Ferrari, M.; Ravera, F. DPPC-DOPC Langmuir monolayers modified by hydrophilic silica nanoparticles: Phase behaviour, structure and rheology. Colloids Surf. A 2012, 413, 174-183. [CrossRef]

27. Guzman, E.; Liggieri, L.; Santini, E.; Ferrari, M.; Ravera, F. Influence of silica nanoparticles on dilational rheology of DPPC-palmitic acid Langmuir monolayers. Soft Matter 2012, 8, 3938-3948. [CrossRef]

28. Guzman, E.; Liggieri, L.; Santini, E.; Ferrari, M.; Ravera, F. Mixed DPPC-cholesterol Langmuir monolayers in presence of hydrophilic silica nanoparticles. Colloids Surf. B 2013, 105, 284-293. [CrossRef]

29. Guzman, E.; Orsi, D.; Cristofolini, L.; Liggieri, L.; Ravera, F. Two-Dimensional DPPC Based Emulsion-like Structures Stabilized by Silica Nanoparticles. Langmuir 2014, 30, 11504-11512. [CrossRef]

30. Orsi, D.; Guzman, E.; Liggieri, L.; Ravera, F.; Ruta, B.; Chushkin, Y.; Rimoldi, T.; Cristofolini, L. 2D dynamical arrest transition in a mixed nanoparticle-phospholipid layer studied in real and momentum spaces. Sci. Rep. 2015, 5. [CrossRef]

31. Guzman, E.; Ferrari, M.; Santini, E.; Liggieri, L.; Ravera, F. Effect of silica nanoparticles on the interfacial properties of a canonical lipid mixture. Colloids Surf. B 2015, 136, 971-980. [CrossRef]

32. Guzman, E.; Santini, E.; Ferrari, M.; Liggieri, L.; Ravera, F. Interfacial Properties of Mixed DPPC-Hydrophobic Fumed Silica Nanoparticle Layers. J. Phys. Chem. C 2015, 119, 21024-21034. [CrossRef]

33. Orsi, D.; Rimoldi, T.; Guzman, E.; Liggieri, L.; Ravera, F.; Ruta, B.; Cristofolini, L. Hydrophobic Silica Nanoparticles Induce Gel Phases in Phospholipid Monolayers. Langmuir 2016, 32, 4868-4876. [CrossRef] [PubMed]

34. Guzman, E.; Santini, E.; Ferrari, M.; Liggieri, L.; Ravera, F. Effect of the Incorporation of Nanosized Titanium Dioxide on the Interfacial Properties of 1,2-Dipalmitoyl-sn-glycerol-3-phosphocholine Langmuir Monolayers. Langmuir 2017, 33, 10715-10725. [CrossRef] [PubMed]

35. Guzman, E.; Liggieri, L.; Santini, E.; Ferrari, M.; Ravera, F. Effect of Hydrophilic and Hydrophobic Nanoparticles on the Surface Pressure Response of DPPC Monolayers. J. Phys. Chem. C 2011, 115, 21715-21722. [CrossRef]

36. Bykov, A.G.; Gochev, G.; Loglio, G.; Miller, R.; Panda, A.K.; Noskov, B.A. Dynamic surface properties of mixed monolayers of polystyrene micro- and nanoparticles with DPPC. Colloids Surf. A 2017, 521, 239-246. [CrossRef]

37. Bykov, A.G.; Guzmán, E.; Rubio, R.G.; Krycki, M.M.; Milyaeva, O.Y.; Noskov, B.A. Influence of temperature on dynamic surface properties of spread DPPC monolayers in a broad range of surface pressures. Chem. Phys. Lipids 2019, 225, 104812. [CrossRef]

38. Sheridan, A.J.; Slater, J.M.; Arnold, T.; Campbell, R.A.; Thompson, K.C. Changes to DPPC Domain Structure in the Presence of Carbon Nanoparticles. Langmuir 2017, 33, 10374-10384. [CrossRef]

39. Bykov, A.G.; Noskov, B.A. Surface Dilatational Elasticity of Pulmonary Surfactant Solutions in a Wide Range of Surface Tensions. Colloid J. 2018, 80, 467-473. [CrossRef]

40. Bykov, A.G.; Loglio, G.; Ravera, F.; Liggieri, L.; Miller, R.; Noskov, B.A. Dilational surface elasticity of spread monolayers of pulmonary lipids in a broad range of surface pressure. Colloids Surf. A 2018, 541, 137-144. [CrossRef]

41. Bykov, A.G.; Loglio, G.; Miller, R.; Milyaeva, O.Y.; Michailov, A.V.; Noskov, B.A. Dynamic properties and relaxation processes in surface layer of pulmonary surfactant solutions. Colloids Surf. A 2019, 573, 14-21. [CrossRef] 
42. Keating, E.; Zuo, Y.Y.; Tadayyon, S.M.; Petersen, N.O.; Possmayer, F.; Veldhuizen, R.A.W. A modified squeeze-out mechanism for generating high surface pressures with pulmonary surfactant. Biochim. Biophys. Acta Biomembr. 2012, 1818, 1225-1234. [CrossRef] [PubMed]

43. Valle, R.P.; Wu, T.; Zuo, Y.Y. Biophysical Influence of Airborne Carbon Nanomaterials on Natural Pulmonary Surfactant. ACS Nano 2015, 9, 5413-5421. [CrossRef] [PubMed]

44. Guzmán, E.; Santini, E.; Zabiegaj, D.; Ferrari, M.; Liggieri, L.; Ravera, F. Interaction of Carbon Black Particles and Dipalmitoylphosphatidylcholine at the Water/Air Interface: Thermodynamics and Rheology. J. Phys. Chem. C 2015, 119, 26937-26947. [CrossRef]

45. Kondej, D.; Sosnowski, T.R. Carbon nanotubes influence surface properties of the phospholipid membrane. Toxicol. Lett. 2018, 295, S203-S204. [CrossRef]

46. Sosnowski, T.R.; Kolinski, M.; Gradon, L. Interactions of Benzo a pyrene and Diesel Exhaust Particulate Matter with the Lung Surfactant System. Ann. Occup. Hyg. 2011, 55, 329-338. [CrossRef]

47. Wang, Z.; Yang, S. Effects of Fullerenes on Phospholipid Membranes: A Langmuir Monolayer Study. ChemPhysChem 2009, 10, 2284-2289. [CrossRef]

48. Wang, Z.; Li, X.; Yang, S. Studies of Dipalmitoylphosphatidylcholine (DPPC) Monolayers Embedded with Endohedral Metallofullerene (Dy@C82). Langmuir 2009, 25, 12968-12973. [CrossRef]

49. Li, S.; Stein, A.J.; Kruger, A.; Leblanc, R.M. Head Groups of Lipids Govern the Interaction and Orientation between Graphene Oxide and Lipids. J. Phys. Chem. C 2013, 117, 16150-16158. [CrossRef]

50. Pavoski, G.; Maraschin, T.; de Carvalho-Fim, F.; Balzaretti, N.M.; Galland, G.B.; Moura, C.S.; de Sousa-Basso, N.R. Few Layer Reduced Graphene Oxide: Evaluation of the Best Experimental Conditions for Easy Production. Matter Res. 2017, 20, 53-61. [CrossRef]

51. Hifeda, Y.F.; Rayfield, G.W. Evidence for First-Order Phase Transitions in Lipid and Fatty Acid Monolayers. Langmuir 1992, 8, 197-200. [CrossRef]

52. Monroy, F.; Ortega, F.; Rubio, R.G.; Velarde, M.G. Surface rheology, equilibrium and dynamic features at interfaces, with emphasis on efficient tools for probing polymer dynamics at interfaces. Adv. Colloid Interface Sci. 2007, 134, 175-189. [CrossRef] [PubMed]

53. Huh, S.H. Thermal Reduction of Graphene Oxide. In Physics and Applications of Graphene Experiment; Mikhailov, S., Ed.; InTech: London, UK, 2011.

54. López-Díaz, D.; Velázquez, M.M.; Blanco de La Torre, S.; Pérez-Pisonero, A.; Trujillano, R.; Fierro, J.L.G.; Claramunt, S.; Cirera, A. The Role of Oxidative Debris on Graphene Oxide Films. ChemPhysChem 2013, 14, 4002-4009. [CrossRef]

55. Claramunt, S.; Varea, A.; López-Díaz, D.; Velázquez, M.M.; Cornet, A.; Cirera, A. The Importance of Interbands on the Interpretation of the Raman Spectrum of Graphene Oxide. J. Phys. Chem. C 2015, 115, 10123-10129. [CrossRef]

56. Hontoria-Lucas, C.; López-Peinado, A.J.; López-González, J.D.D.; Rojas-Cervantes, M.L.; Martin-Aranda, R.M. Study of oxygen-containing groups in a series of graphite oxides: Physical and chemical characterization. Carbon 1995, 33, 1585-1592. [CrossRef]

57. Yang, D.; Velamakanni, A.; Bozoklu, G.; Park, S.; Stoller, M.; Piner, R.D.; Stankovich, S.; Jung, I.; Field, D.A.; Ventrice, C.A.; et al. Chemical analysis of graphene oxide films after heat and chemical treatments by $\mathrm{X}$-ray photoelectron and Micro-Raman spectroscopy. Carbon 2009, 47, 145-152. [CrossRef]

58. Klopfer, K.J.; Vanderlick, T.K. Isotherms of Dipalmitoylphosphatidylcholine (DPPC) Monolayers: Features Revealed and Features Obscured. J. Colloid Interface Sci. 1996, 182, 220-229. [CrossRef]

59. Arriaga, L.R.; Löpez-Montero, I.; Ignés-Mullol, J.; Monroy, F. Domain-growth kinetic origin of nonhorizontal phase coexistence plateaux in langmuir monolayers: Compression rigidity of a raft-like lipid distribution. J. Phys. Chem. B 2010, 114, 4509-4520. [CrossRef]

60. Phillips, M.C.; Chapman, D. Monolayer characteristics of saturated 1,2-diacyl phosphatidylcholines (lecithins) and phosphatidylethanolamines at the air-water interface. Biochim. Biophys. Acta Biomembr. 1968, 163,301-313. [CrossRef]

61. Gaines, G.L. Insoluble Monolayers at Liquid-Gas Interfaces; Interscience Publishers: New York, NY, USA, 1966.

62. Dynarowicz-Łatka, P.; Kita, K. Molecular interaction in mixed monolayers at the air/water interface. Adv. Colloid Interface Sci. 1999, 79, 1-17. [CrossRef] 
63. Petrov, J.G.; Andreeva, T.D.; Moehwald, H. Dipolar Interactions and Miscibility in Binary Langmuir Monolayers with Opposite Dipole Moments of the Hydrophilic Heads. Langmuir 2009, 25, 3659-3666. [CrossRef]

64. Ravera, F.; Ferrari, M.; Santini, E.; Liggieri, L. Influence of surface processes on the dilational visco-elasticity of surfactant solutions. Adv. Colloid Interface Sci. 2005, 117, 75-100. [CrossRef] [PubMed]

(C) 2020 by the authors. Licensee MDPI, Basel, Switzerland. This article is an open access article distributed under the terms and conditions of the Creative Commons Attribution (CC BY) license (http://creativecommons.org/licenses/by/4.0/). 